\title{
Packaging and testing of fiber Bragg gratings for use as strain sensor in rock specimens
}

\author{
Alvaro Castro-Caicedo ${ }^{\mathrm{a}}$, Pedro Torres ${ }^{\mathrm{b}}$, Ricardo Lain ${ }^{\mathrm{c}}$ \\ ${ }^{a}$ Facultad de Minas, Universidad Nacional de Colombia, Sede Medellín, \\ Carrera 80 65-223, Medellín, Colombia. \\ ajcastro@unal.edu.co \\ ${ }^{\mathrm{b}}$ Escuela de Física, Universidad Nacional de Colombia, Sede Medellín, A.A. 3840, \\ Medellín, Colombia. \\ ${ }^{c}$ Escuela Técnica Superior de Ingenieros de Minas, Universidad Politécnica de Madrid, Ríos Rosas \\ 21, Madrid, Spain.
}

\begin{abstract}
This paper reports a packaging and calibration procedure for surface mounting of fiber Bragg grating (FBG) sensors to measure strain in rocks. The packaging of FBG sensors is performed with glass fiber and polyester resin, and then subjected to tensile loads in order to obtain strength and deformability parameters, necessaries to assess the mechanical performance of the sensor packaging. For a specific package, an optimal curing condition has been found, showing good repeatability and adaptability for non-planar surfaces, such as occurs in rock engineering.

The successfully packaged sensors and electrical strain gages were attached to standard rock specimens of gabbro. Longitudinal and transversal strains under compression loads were measured with both techniques, showing that response of FBG sensors is linear and reliable. An analytical model is used to characterize the influences of rock substrate and FBG packaging in strain transmission. As a result, we obtained a sensor packaging for non-planar and complex natural material under acceptable sensitivity suitable for very small strains as occurs in hard rocks.
\end{abstract}

Keywords: Optical fiber, fiber Bragg gratings, sensor, rock, gabbro.

\section{INTRODUCTION}

Fiber Bragg grating (FBG) sensors have attracted a considerable amount of interest in the last ten years for use in opticalfiber sensing applications in civil and structural engineering. Geotechnical engineering needs reliable and precise information on stress, strain, and temperature in their states, rates, and gradients both in-situ and under laboratory conditions [1]. To date, however, there are only a few cases where FBG strain sensors have been used for rock deformation $[1,2]$. Other applications of FBG sensors in geotechnical engineering include dynamic monitoring of tunnel displacements [3], and in downhole measurements [4]. However, these sensors are fragile and their packaging should ensure that the sensors are robust and rugged enough to withstand the harsh environment found in the geotechnical industry.

In this work, we describe, for the first time, the feasibility of a FBG sensor application in hard rock mechanical material testing. The packaging of FBG sensors is performed with glass fiber and polyester resin. An optimal curing condition has been found, obtaining a sensor packaging for non-planar and complex natural material under acceptable sensitivity suitable for very small strains as occurs in hard rocks. We used an analytical model to characterize the influences of rock substrate and FBG packaging in strain transmission. Longitudinal and transversal strains under compression loads were measured, showing that response of FBG sensors is linear and reliable.

\section{FBG STRAIN SENSOR PACKAGING}

According to some researchers [5], the materials have been used for sensor packaging in engineering industry are glass fiber reinforced polymer (GRP), carbon fiber reinforced polymer (CFRP), epoxy resin, and synthetic fibers (SFRP). Two

8th Iberoamerican Optics Meeting and 11th Latin American Meeting on Optics, Lasers, and Applications,

edited by Manuel Filipe P. C. Martins Costa, Proc. of SPIE Vol. 8785,87852 R

(C) 2013 SPIE $\cdot$ CCC code: $0277-786 X / 13 / \$ 18 \cdot$ doi: $10.1117 / 12.2025678$ 
main ideas guided this research: firstly, GRP was selected because it is an economical material, and secondly, we have tried to achieve an acceptable reliability level about sensor capability, thus, the strain transmission from the rock to the FBG sensor needs to be analyzed.

The FBG strain sensor packaging consists of two GRP layers. The sensor system is $100 \mathrm{~mm}$ long, $25 \mathrm{~mm}$ wide and 0.5 $\mathrm{mm}$ thick, and is fixed to the rock substrate with a very thin layer of adhesive. The two-dimensional arrangement provides less stiffness and strength in the through-thickness direction because these properties are determined by the low mechanical properties of the resin and fiber-to-resin interface. Fig. 1 shows the manufacturing process of the sensor packaging.

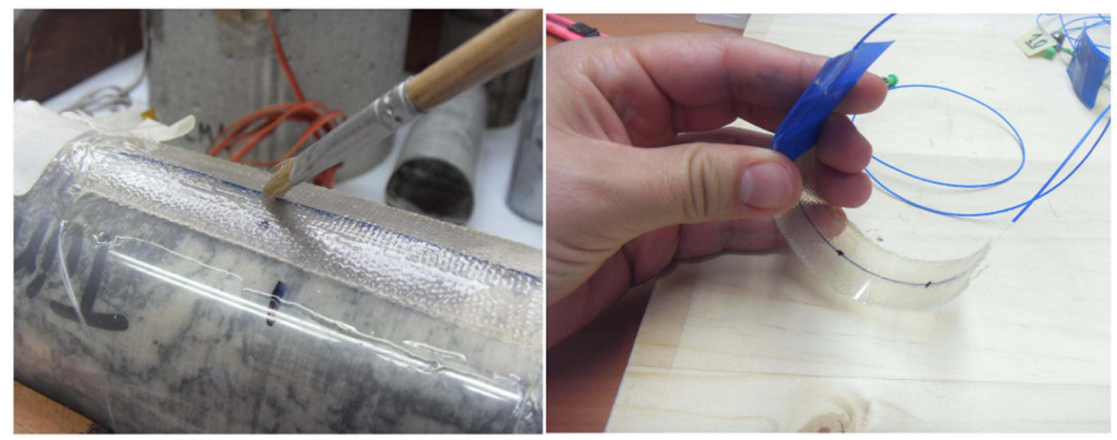

Figure 1. Manufacturing of sensor packaging. The FBG sensor and the glass fiber woven tape were spread with polymeric resin adopting semi-circular shape to obtain a sensor packaging for non-planar geometry.

For an FBG bonded to the surface of a substrate, an analytical model for the bonding layer that glues the FBG and substrate together is need. An unacceptable bonding layer fails to transfer enough strain from the substrate to the FBG. Some researchers have concluded than the strain transmission loss becomes large when the substrate is thin and/or made by a low modulus material [6]. The FBG and the bonding layer affect the original strain distribution on the thin and lowmodulus substrate; as a result, the substrate strain sensed by the FBG is underestimated and thus required to be corrected.

Consider an FBG of diameter $\mathrm{tF}$ and Young's modulus $\mathrm{E}_{\mathrm{F}}$ bonded onto the surface of a substrate of thickness $\mathrm{t}_{\mathrm{S}}$ and Young's Modulus $E_{S}$ as shown in Fig. 2. Assume that the cross-sectional area of the FBG is much smaller than that of the substrate, when the substrate is subjected to an external force F, the bonded FBG senses the strain of the substrate transferred through the bonding layer of thickness $\mathrm{tB}$.
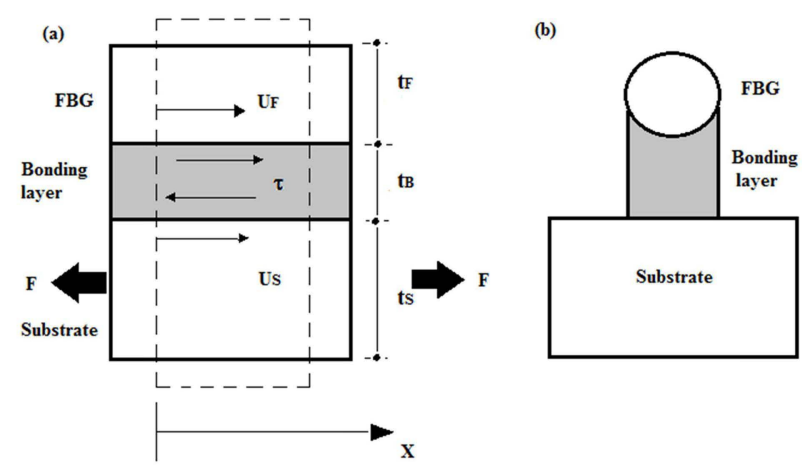

Figure 2. FBG surface bonded on a substrate (a) one-dimensional free-body diagram and (b) cross-sectional view. 
The strain transferred from the substrate through the bonding layer to the FBG is quantified by the strain transmission rate defined as

$$
\mathrm{k}=\frac{\epsilon \mathrm{F}}{\epsilon \mathrm{T}}
$$

Where $\epsilon \mathrm{F}$ is the strain measured by the $\mathrm{FBG}$ and $\epsilon \mathrm{T}$ is the true strain of the substrate. For a perfect bonding, the strain sensed by the FBG is the same as that of the rock substrate, and $\mathrm{k}=1$.

The sensor packaging was glued to rock with Loctite 330 methacrylate adhesive. Thus, the strain transmission rate can be expressed as presented by Li [6].

$$
\mathrm{k}=\left(\frac{\mathrm{E}_{\mathrm{S}} \mathrm{t}_{\mathrm{S}}}{\mathrm{E}_{\mathrm{S}} \mathrm{t}_{\mathrm{S}}+\mathrm{E}_{\mathrm{F}} \mathrm{t}_{\mathrm{F}}}\right)^{2}
$$

The strain transmission rate calculated using equation (2) is showed in Fig. 3 for a $63 \mathrm{~mm}$ rock specimen diameter, the packaging thickness and the Young's Modulus are $0.48 \mathrm{~mm}$ and $12.785 \mathrm{GPa}$ respectively, as previously obtained in laboratory tests. As we can see, the strain transmission rate is higher $95 \%$ when the rock Young's Modulus is above 5 $\mathrm{GPa}$. A range of values between 5 and $25 \mathrm{GPa}$ are usual for many kind of rocks and concrete materials.

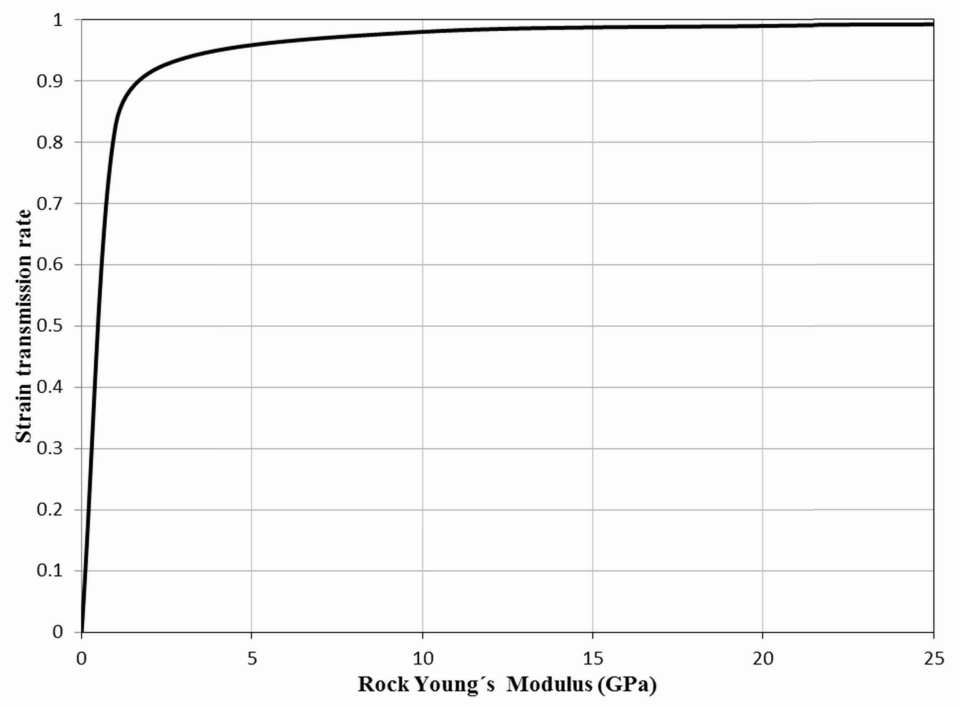

Figure 3. Strain transmission rate for a rock specimen with Young's modulus ranging from 0 to $25 \mathrm{GPa}$.

\section{EXPERIMENTAL SETUP}

After packaging, a calibration process for using the FBG as strain sensor is needed. With this aim, longitudinal and transversal strain of rock specimens under compressive load was measured with FBG sensors and electrical strain gages.

The loading device system was a hydraulic Pilot Controls $4 x 4$, with a capacity up to 200 t. The ASTM, laboratory method used to obtain elastic moduli and compressive strength of rock samples, recommends a load rate between 0.5 and $1.0 \mathrm{MPa} / \mathrm{s}$ [7]. However, in order to notice the influence of the compressive load on the FBG sensor performance, three tests were developed with load rates $0.1,0.5$ and $1.0 \mathrm{MPa} / \mathrm{s}$. Fig. 4 shows a schematic of the experimental setup and images of rock samples in the loading system with properly attached FBG sensors.

A tunable Fabry-Perot filter system from Micron Optics Inc. has been used as readout unit for the FBG strain sensors (see Fig. 5). This interrogation technique allows the simultaneous detection of several sensors in series; their total number depends on the expected dynamic range of strain. The system has a temperature-stabilized fixed Fabry-Perot multiwavelength reference to achieve stability and accuracy of $5 \mathrm{pm}$ at one measurement per second. 

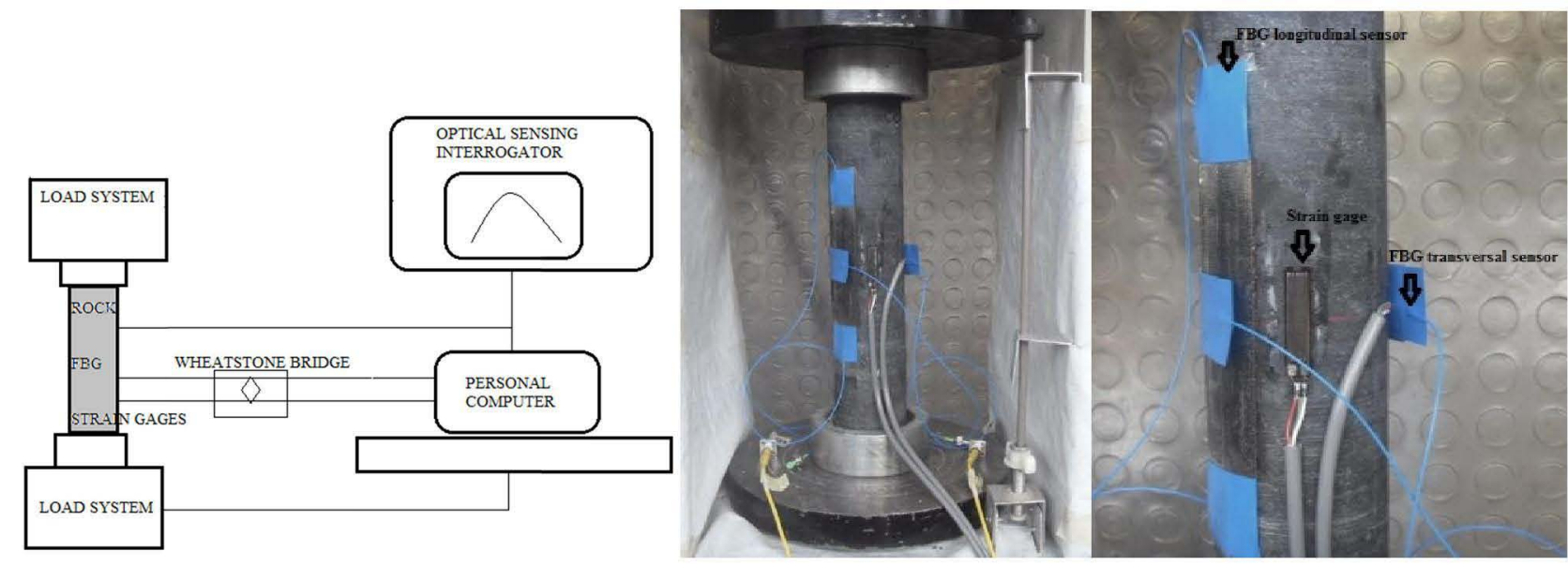

Figure 4. Experimental set-up and rock samples in the loading device. Gabbro rock specimen under compression load; 10 $\mathrm{cm}$ long FBG sensor packaging is visible.

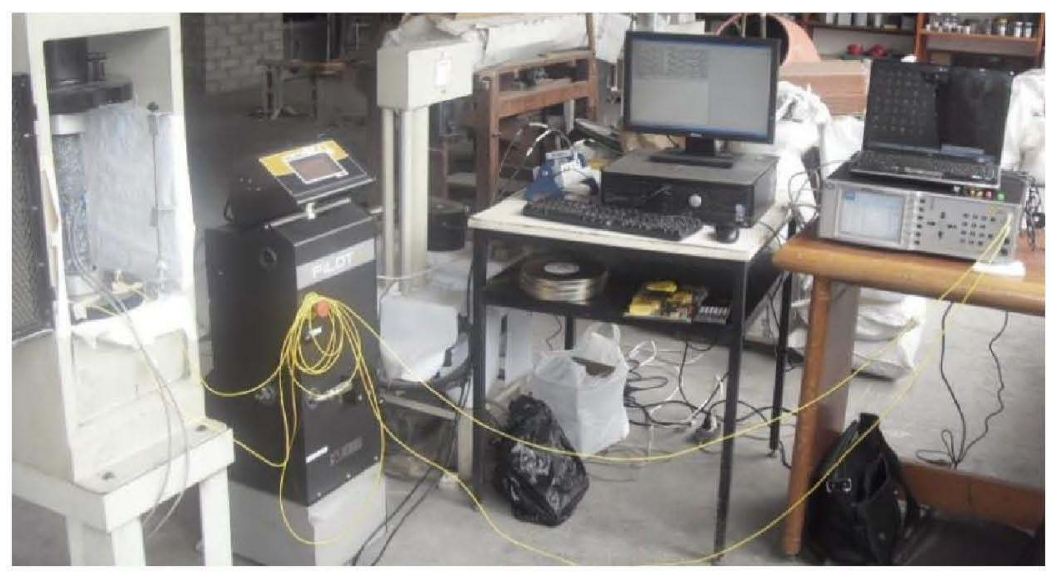

Figure 5. Experimental set-up showing compression loading device, micron-optics interrogator and strain gage data acquisition system.

\section{EXPERIMENTAL RESULTS}

Relationships were obtained for wavelength; strain and loading for uniaxial compression on rock samples. Fig. 6 shows axial force-axial elastic strain curve for gabbro. Fig. 7 shows the results measured for load and wavelength; it is visible that wavelength shifts are suitable for sensing small loading changes.

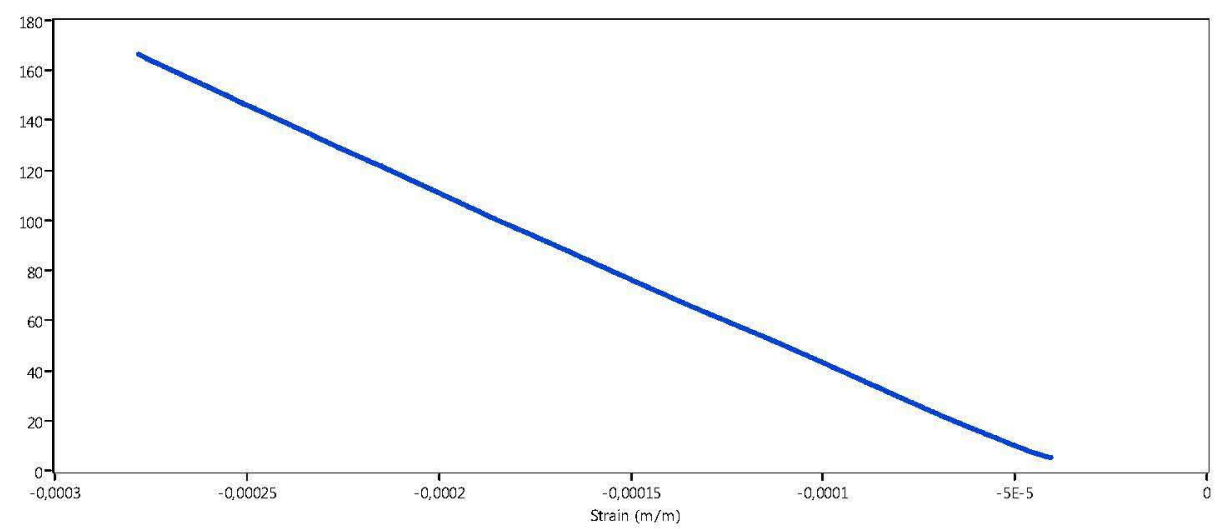

Figure 6. Results obtained in the uniaxial compression test on rock. The length reduction is considered as negative. 


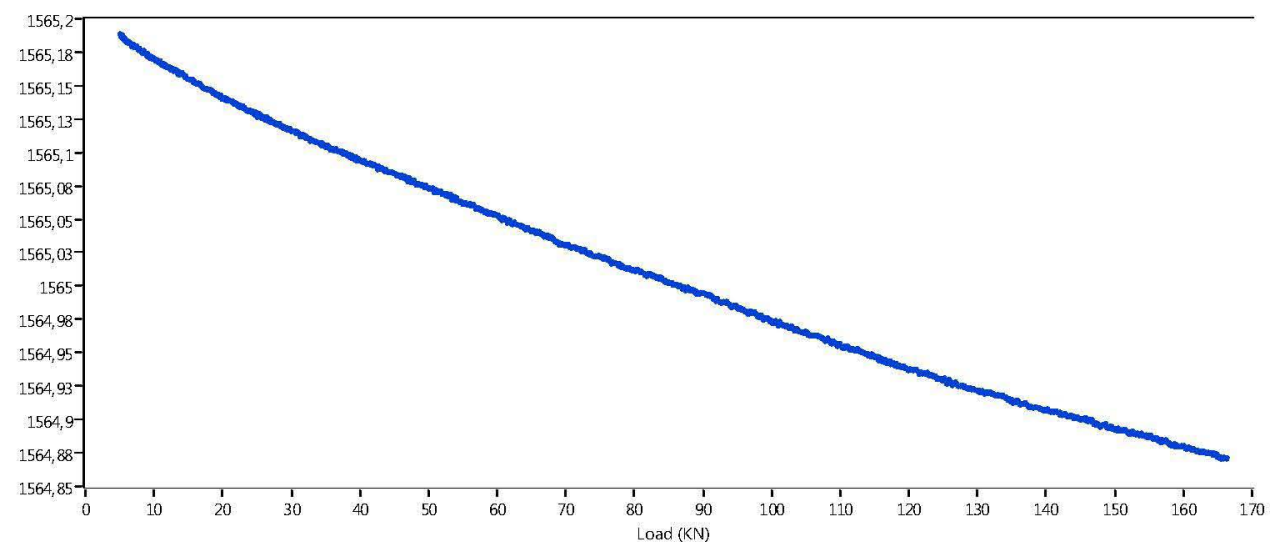

Figure 7. Relation between uniaxial compression loads and wavelength readings obtained with FBG sensor.

Figures 8 and 9 shows recorded strain range between -275 to +100 microstrain; commercial products such as Geokon Fiber Optic FP4000 reaches ranges between -1000 to +1000 microstrain [9]. Otherwise, [1] reports -4 orders of magnitude for strain sensing; in this work we achieved $\mathbf{- 5}$ orders of magnitude for longitudinal and transversal strain. It is visible that equal strain is recorded with different wavelengths, possibly due to the time-dependent effect of the rock under different load rates.

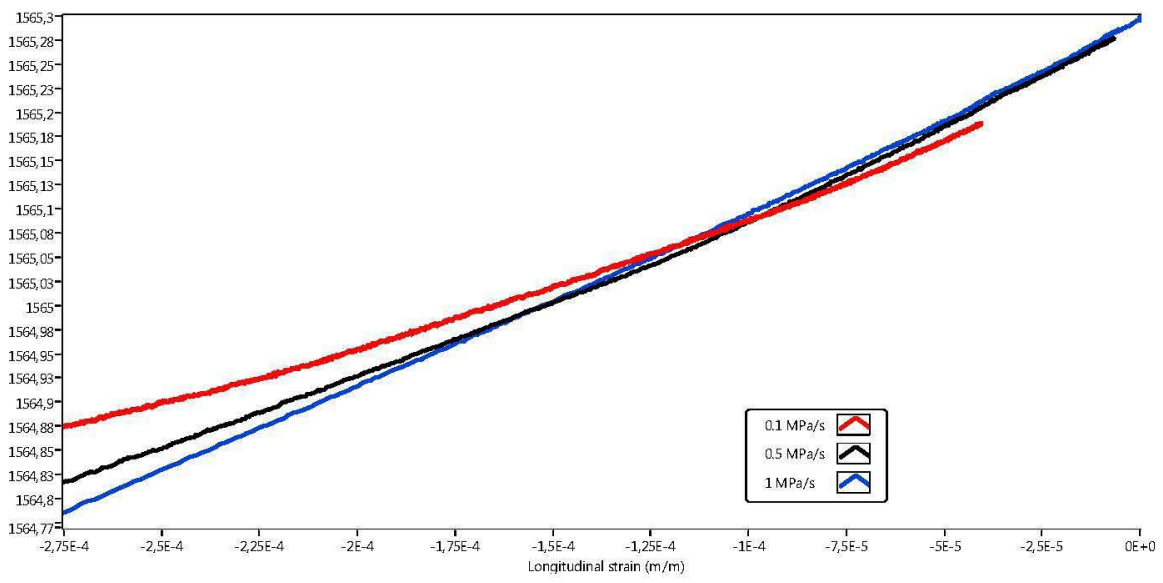

Figure 8. Longitudinal strain and wavelength response of FBG sensors for $0.1,0.5$ and $1 \mathrm{MPa} / \mathrm{s}$ load rates. FBG sensors were able to detect from 0 to 275 microstrains. 


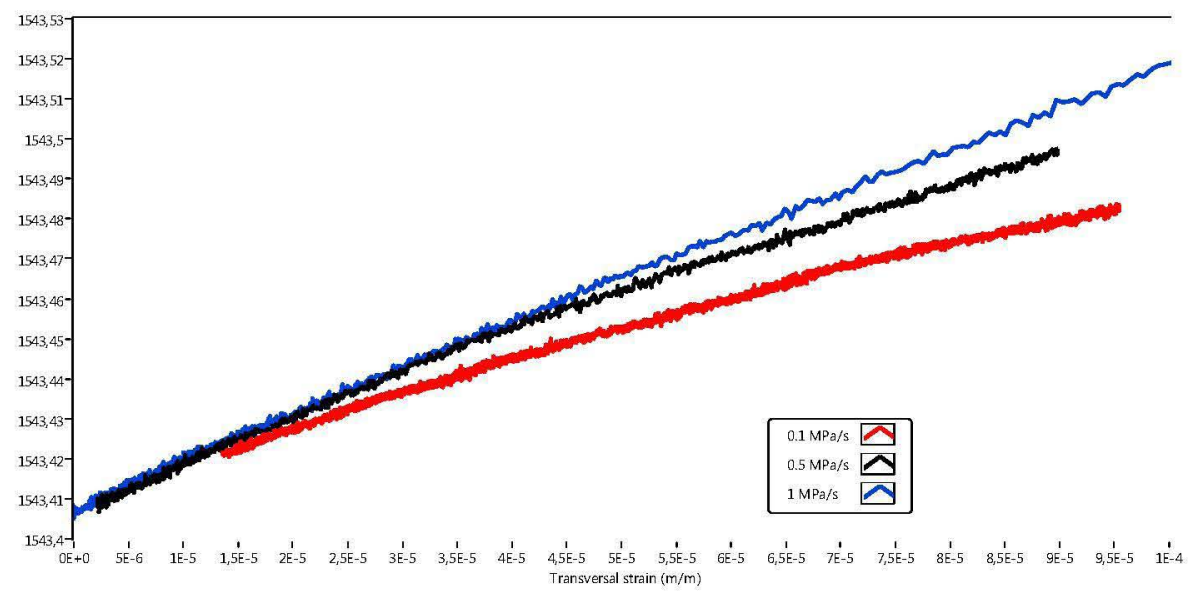

Figure 9. Transversal strain response of FBG sensors for $0.1,0.5$ and $1 \mathrm{MPa} / \mathrm{s}$ load rates. FBG sensors were able to detect from 0 to 100 microstrains.

For an FBG of $1550 \mathrm{~nm}$ central wavelength, the typical strain sensitivity is $1.2 \mathrm{pm} /$ microstrain [8]. The longitudinal and transversal sensor sensitivity obtained in these tests is presented en Table 1.

Table 1. Sensitivity of the FBG strain sensors for different compressive load rates.

\begin{tabular}{|l|l|l|}
\hline \multirow{2}{*}{$\begin{array}{c}\text { Load rate } \\
\mathbf{M P a} / \mathbf{s}\end{array}$} & \multicolumn{2}{|c|}{ Sensitivity $\mathbf{~ p m} / \mathbf{m i c r o s t r a i n}$} \\
\cline { 2 - 3 } & Longitudinal & Transversal \\
\hline 0.1 & 1.3 & 0.8 \\
\hline 0.5 & 1.6 & 1.0 \\
\hline 1 & 1.7 & 1.1 \\
\hline
\end{tabular}

\section{CONCLUSIONS}

FBG sensors have been used in civil engineering, in materials such as concrete and metals. Very few works have been reported for use in rocks. This work presents a new surface-bonded FBG sensor designed to measure strains on nonplanar rock samples, as required for laboratory tests, and defines an initial step for future applications in rock structures, underground excavations, and geotechnical uses. The sensor packaging technique allows indeed a good transfer of strain, leading to testing in hard rock. Here is demonstrated strain ranges in rocks a few tens of microstrain.

The possible influence of rock inhomogeneities is diminished due to increased effective measurement area of the FBG sensor packaging. Sensor adaptation to different geometries allows a wide variety of applications.

Otherwise, in [10] was concluded that the thickness and Young's modulus of the adhesive have little influence on the strain transmission, especially with the thickness of the glue is less than the diameter of an optical fiber, as made in this work.

\section{Acknowledgments}

The authors acknowledge the Universidad Nacional de Colombia (Programa de apoyo para el fortalecimiento de grupos de investigación que apoyan programas de posgrado-2012, grant number 90201022), and the project: Alianza para la fabricación y prueba industrial de instrumentación geotécnica con base en sensores de fibra óptica. 


\section{REFERENCES}

[1] Schmidt-Hattenberger C., Naumann M., Borm G. "Fiber Bragg grating strain measurements in comparison with additional techniques for rock mechanical testing," IEEE Sensors Journal, 3, No. 1, 50-55 (2003).

[2] J. R. Moore, V. Gischig, E. Button, and S. Loew, "Rockslide deformation monitoring with fiber optic strain sensors," Nat. Hazards Earth Syst. Sci., 10, 191-201 (2010).

[3] Schmidt-Hattenberger, C., Borm, G., Amberg, F., "Bragg grating seismic monitoring system," Proc. SPIE Conference on Fiber Optic Sensor Technology and Applications, 417-424 (1999).

[4] A. D. Kersey, "Optical fiber sensors for permanent downwell monitoring applications in the oil and gas industry," IEICE Trans. Electron., E83-C, 400-404 (2000).

[5] Horoschenkoff A. Klein S., Haase K., "Structural integration of strain gages," HBM Measurements. (20 June 2013). $\leq$ http://www.hbm.com/es/menu/consejos-y-trucos/analisis-experimental-de-tensiones/structural-integration-ofstrain-gages/

[6] Li, W.Y., Cheng C.C., Lo Y.L. "Investigation of strain transmission of surface-bonded FBGs used as strain sensors," Sensors and Actuators A 149. 201-207 (2009).

[7] ASTM D7012. "Compressive strength and elastic moduli of intact rock core specimens under varying states of stress and temperatures," Philadelphia USA, (2010).

[8] Li D., Li H., Ren L., Song G. "Strains transferring analysis of fiber Bragg grating sensors," Optical Engineering 45(2). SPIE International Society for Optics and Photonics (2006).

[9] <http://www.geokon.com/fiber-optic-strain-gages/ (20 june 2013)

[10] Y. B. Lin., K. C. Chang., J. C. Chern., L. A. Wang. "Packaging Methods of Fiber-Bragg Grating Sensors in Civil Structure Applications," IEEE Sensors Journal, 5, 419-424 (2005). 